\title{
BMJ Open Relationship between estimated cardiovascular disease risk and insulin resistance in a black African population living with HIV: a cross-sectional study from Cameroon
}

\author{
Steve Raoul Noumegni, ${ }^{1,2}$ Jean Joel Bigna, ${ }^{2,3}$ \\ Vicky Jocelyne Ama Moor epse Nkegoum, ${ }^{4,5}$ Jobert Richie Nansseu, ${ }^{6}$ \\ Felix K Assah, ${ }^{6}$ Ahmadou Musa Jingi, ${ }^{7}$ Magellan Guewo-Fokeng, ${ }^{8,9}$ Steve Leumi, ${ }^{8,9}$ \\ Jean-Claude Katte, ${ }^{10}$ Mesmin Y Dehayem, ${ }^{10}$ Liliane Mfeukeu Kuate, ${ }^{7,11}$ \\ Andre Pascal Kengne, ${ }^{12,13}$ Eugene Sobngwi ${ }^{7,9,10}$
}

To cite: Noumegni SR, Bigna JJ, Ama Moor epse Nkegoum VJ, et al. Relationship between estimated cardiovascular disease risk and insulin resistance in a black African population living with HIV: a cross-sectional study from Cameroon. BMJ Open 2017;7:e016835. doi:10.1136/ bmjopen-2017-016835

- Prepublication history for this paper is available online. To view these files please visit the journal online (http://dx.doi. org/10.1136/bmjopen-2017016835).

Received 13 March 2017 Revised 16 June 2017 Accepted 12 July 2017

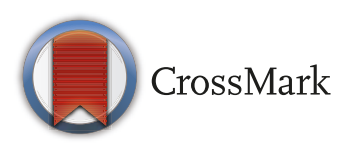

For numbered affiliations see end of article.

Correspondence to Dr Steve Raoul Noumegni; stevenoumegni91@yahoo.com

\section{ABSTRACT}

Objectives Cardiovascular disease (CVD) and metabolic diseases are growing concerns among patients with HIV infection as a consequence of the improving survival of this population. We aimed to assess the relationship between CVD risk and insulin resistance in a group of black African individuals with HIV infection.

Methods This cross-sectional study involved patients with HIV infection aged 30-74 years and followed up at the Yaoundé Central Hospital, Cameroon. Absolute CVD risk was calculated using the Framingham and the DAD CVD risk equations while the HOMA-IR index was used to assess insulin resistance (index $\geq 2.1$ ).

Results A total of 452 patients (361 women; 80\%) were screened. The mean age was 44.4 years and most of the respondents were on antiretroviral therapy $(88.5 \%)$. The median 5-year cardiovascular risk was $0.7 \%$ (25th-75th percentiles: $0.2-2.0)$ and $0.6 \%(0.3-1.3)$ according to the Framingham and DAD equations respectively. Of all participants, $47.3 \%$ were insulin resistant. The Framingham equation derived absolute CVD risk was significantly associated with insulin resistance; while no linear association was found using the DAD equation. Conclusion The relationship between cardiovascular risk and insulin resistance in black African patients with HIV infection seems to depend on the cardiovascular risk equation used.

\section{INTRODUCTION}

In 2015, there were 36.7 million people living with HIV globally. As of June 2016, nearly $50 \%$ of them were accessing antiretroviral therapy (ART). ${ }^{1}$ Since the advent and widespread use of continuous ART, the life expectancy of people living with HIV has considerably increased, with a concomitant significant reduction in related mortality. In fact, opportunistic illness associated
Strengths and limitations of this study

- To the best of our knowledge, this is the first study which assessed the direct relationship between cardiovascular risk and insulin resistance as continuous variables among people with HIV infection in sub-Saharan Africa.

- Rigorous methodological and statistical procedures were used to examine our research questions.

- This study aptly highlighted that the relationship between cardiovascular risk and insulin resistance in patients with HIV infection in sub-Saharan Africa depends on the cardiovascular risk equation used.

- The sampling method was not random, perhaps hindering the external validity of our results.

- An indirect method was used to assess insulin resistance instead of the hyperinsulinemic euglycemic clamp which is the gold standard.

with AIDS has drastically declined in this specific population, leading to an increase in life quality gain. ${ }^{2}$ However, this is not without any drawback effect. Indeed, there is a body of evidence showing an increase in the burden of non-communicable diseases (NCDs) collectively with their risk factors among individuals with HIV infection. ${ }^{3}$ Accordingly, the prevalence and burden of cardiovascular disease (CVD) and metabolic complications tend to grow within this population, occurring even at younger ages than in the general population. ${ }^{34}$ In the last decade, despite the remarkable progress noted in the management of HIV infection worldwide, HIV/AIDS-related deaths, although in gradual decline, remain significant. ${ }^{1}$ This is essentially the result of non-communicable 
comorbidities led by cardiovascular and metabolic diseases. $^{4}$

NCDs kill more than 36 million people each year and $80 \%$ occur in low and middle income countries, including most people in Africa. People infected with HIV therefore present a double burden of disease due to a close relationship between HIV, ART and CVD. For instance, HIV increases twofold the risk of coronary heart disease. ${ }^{5}$ Moreover, HIV and ART are recognised as independent factors associated with metabolic complications. ${ }^{67}$ The mechanism of the increased risk of CVD among people with HIV infection is multifactorial, mainly supported by two well described metabolic disorders, including dyslipidaemia and insulin resistance, both of which result from the probable complex interaction between the host's advancing age, the virus, the inflammatory process, and ART. ${ }^{2}$ In this regard, evidence suggests a higher prevalence of insulin resistance in HIV-infected populations than in the general population. ${ }^{8}$

To better tackle the increasing burden of CVDs in patients with HIV infection, all mechanisms implicated in CVD occurrence should be clearly elucidated and subsequently attacked. However, studies investigating the existence of any association between insulin resistance and cardiovascular risk factors in HIV-infected black Africans are scarce. Therefore, we designed the present study, which aimed to examine the following question: what is the relationship between insulin resistance and absolute CVD risk in a group of black African people living with HIV?

\section{METHODS}

\section{Ethical considerations}

The study was approved by the Cameroon National Ethics Committee for Human Health Research (Ethical approval No 2015/12/710/CE/CNERSH/SP). All participants signed the informed consent form.

\section{Study design and participants}

This cross-sectional study was conducted from December 2015 to May 2016 at the HIV day-care unit of the Yaoundé Central Hospital. All apparently healthy patients aged 30-74 were included, unless they had a history of CVD, were pregnant or breastfeeding, or were on lipid-lowering therapy or hormone therapy.

\section{Data collection}

Socio-demographic characteristics, history of HIV infection, and cardiovascular risk factors were collected. Family history of early CVD was defined as CVD in a first-degree male relative before the age of 55 or in a first-degree female relative before the age of $65 .{ }^{9}$ Smoking status was classified as never, former or current. Hazardous alcohol drinking was defined by an AUDIT-C (Alcohol Use Disorders Identification Test-Consumption) score $\geq 4$ for men and $\geq 3$ for women. ${ }^{10}$ Lack of physical activity was defined as absence of walking or any other intense physical activity at least once a week. ${ }^{11}$ Participants' stage of HIV infection was classified using the WHO clinical staging for HIV infection. ${ }^{12}$ Body mass index (BMI) was classified as recommended by WHO. ${ }^{13}$ Abdominal obesity was defined in accordance with the International Diabetes Federation (IDF) ${ }^{14}$ High blood pressure was defined as a systolic blood pressure (SBP) $\geq 140 \mathrm{mmHg}$ and/ or a diastolic blood pressure (DBP) $\geq 90$ and/or self-reported history of antihypertensive medication. ${ }^{15}$ Insulin was indirectly estimated by measuring the C-peptide level, using the sandwich immunoassay method (ELISA method). Dyslipidaemia was considered as an elevated level of total cholesterol (TC) $(>6.2 \mathrm{mmol} / \mathrm{L})$ and/or an elevated level of low-density lipoprotein cholesterol (LDL-C) $(>4.1 \mathrm{mmol} / \mathrm{L})$ and/or a low level of high-density lipoprotein cholesterol (HDL-C) $(<1.04 \mathrm{mmol} / \mathrm{L}$ in men and $1.29 \mathrm{mmol} / \mathrm{L}$ in women) and/or hypertriglyceridaemia $(\geq 1.7 \mathrm{mmol} / \mathrm{L}) .{ }^{16}$ We considered any patient as having diabetes when there were at least 2 fasting plasma glucose (FPG) levels $\geq 7.0 \mathrm{mmol} / \mathrm{L}$ on two occasions at least 48 hours apart, or self-reported ongoing use of antidiabetes medications following a diagnosis made in a health facility. ${ }^{17}$ Metabolic syndrome was defined using the International Diabetic Federation criteria. ${ }^{14}$

\section{CVD risk assessment}

The 5-year risk of CVD was calculated using two equations: a non-specific equation (the FraminghamAnderson equation) ${ }^{18}$ and a specific equation applied to people living with HIV (the DAD equation). ${ }^{19}$

\section{Insulin resistance evaluation}

The HOMA-IR index served to assess the insulin sensitivity; it was determined by the formula: fasting blood glucose $(\mathrm{mmol} / \mathrm{L}) \times$ fasting Insulin $(\mathrm{mU} / \mathrm{L}$ or $\mu \mathrm{Ul} /$ $\mathrm{mL}) / 22.5 .^{20}$ Insulin resistance was defined by any value of the HOMA-IR index equal or above 2.1; this threshold was defined in an HIV-infected population in Peru. ${ }^{5}$

\section{Statistical analysis}

Data were analysed using the Statistical Package for Social Sciences (SPSS) software, version 23.0 (IBM SPSS Inc, Chicago, Illinois, USA). Results are presented as frequency (percentage) for categorical variables; and mean \pm SD deviation (SD) or median (25th-75th percentiles) for continuous variables. Qualitative variable comparisons used the $\chi^{2}$ test. Likewise, the Student $t$-test or non-parametric equivalents served for quantitative variable comparisons. Univariable and multivariable linear regression analyses were undertaken to investigate the relationship between CVD risk and insulin resistance. We introduced in the multivariable model all variables with a p-value $<0.25$ in the univariable model as recommended by the purposeful selection process, ${ }^{21}$ in addition to the HOMA-IR index regardless of its p-value obtained in univariable analysis. We used backward elimination to retain the final significant predictors in the model. A $p$-value $<0.05$ was considered of statistical significance. 


\section{RESULTS}

\section{Characteristics of the study population}

Overall, we included 452 patients among whom 361 (79.9 $\%)$ were women. The mean age was $44.4 \pm 9.8$ years. Of the 452 participants, $400(88.5 \%)$ were on continuous ART. The study population's characteristics are presented in table 1 .

\section{Assessment of the 5-year risk of CVD and insulin resistance} Calculated with the DAD equation, the 5-year risk of CVD ranged from $0.1 \%$ to $13.3 \%$, with a median of $0.6 \%(0.3-$ 1.3). The 5-year risk of CVD estimated by the Framingham equation ranged from $0.0 \%$ to $20.7 \%$ with a median of $0.7 \%(0.2-2)$.

The median HOMA-IR index was 2.1 (1.4-3.2).

\section{Relationship between CVD risk and insulin resistance}

The CVD risk (estimated using the Framingham equation) of participants with insulin resistance was higher than that of participants without this condition: $4.1 \%$ $(2.5-5.6)$ versus $2.2 \%(1.7-3.7) ; \mathrm{p}<0.001$. But using the DAD equation, there was no difference between CVD risk of participants with insulin resistance and those without: $1.9 \%(1.4-2.9)$ versus $1.5 \%(1.1-2.5) ; \mathrm{p}=0.102$.

In univariable analysis, there was no linear significant association between the CVD risk (estimated using the DAD equation) and the HOMA-IR index ( $\beta=0.03$; $\mathrm{p}=0.717$ ) as well as between this risk and categorical insulin resistance $(\beta=0.12 ; \mathrm{p}=0.156)$; however, using the CVD risk assessed with the Framingham equation, this relation became statistically significant: HOMA-IR $(\beta=0.28$; $p=0.002)$; categorical insulin resistance $(\beta=0.17 ; p=0.033)$ (table 2). The regression equations of these associations are presented below. In multivariable analysis, the association between the CVD risk (assessed using the DAD equation) and the HOMA-IR index remained non-significant $(\beta=0.18 ; p=0.429)$ (table 3$)$. On the contrary, this association using the Framingham equation remained statistically significant $(\beta=0.64 ; p=0.001)$ (table 3$)$.

Relationship between CVD risk (DAD score based) and HOMA-IR index:

$\mathrm{Y}=0.0069 \mathrm{x}+1.8324\left(\mathrm{R}^{2}=0.001\right)$.

Relationship between CVD risk (Framingham score based) and HOMA-IR index:

$\mathrm{Y}=0.01052 \mathrm{x}+2.7622\left(\mathrm{R}^{2}=0.0774\right)$.

\section{DISCUSSION}

The general objective of this study was to evaluate the relationship between CVD risk and insulin resistance among patients with HIV infection in Cameroon. As key findings, we observed that the relationship between CVD risk and insulin resistance varied depending on the risk equation used. Indeed, using the Framingham risk equation, participants with insulin resistance had a higher risk of CVD compared with their counterparts without insulin resistance. Additionally, the relationship between CVD risk and the HOMA-IR index was significant in univariable analysis as well as in multivariable linear regression analysis after adjusting for confounders. By contrast, all these linear associations were insignificant when the CVD risk was estimated with the DAD risk equation.

Calculated using the Framingham equation or the DAD equation, the median CVD risk was lower in our study population. This can be explained by the relatively young age of our participants and the high proportion of females $(80 \%)$. Indeed, the male sex is recognised as an independent risk factor for CVD. ${ }^{22}$ Using either the Framingham or the DAD equations, we found that the proportion of subjects decreased progressively with increasing degree of cardiovascular risk. These results are similar to those already reported..$^{2324}$ and are probably due to the relative young age of the majority of our study population.

In this study, insulin resistance had a higher prevalence than that found by Guillen et al in a population of 219 people with HIV infection in Peru $(34.2 \%)$ while using the same HOMA-IR definition threshold. ${ }^{5}$ Moreover, Guillen et al reported a mean value of HOMA-IR index of $2.6 \pm 3$ less than that found in our study $(3.85 \pm 5.87)$. This difference may be due to the fact that the basal insulin secretion is high in African populations. ${ }^{25}$

We found no significant relationship between insulin resistance and CVD risk calculated using the DAD equation. Indeed, there was no significant association between HOMA-IR index and CVD risk calculated using this equation. Considering the Framingham equation, we found a significant association between CVD risk and insulin resistance in univariate analysis and after adjustment for other factors in the multivariate analysis. These results were the same when considering the linear association between CVD risk and HOMA-IR index as a continuous variable or a categorical one (defining insulin resistance). Thus, based on our results, there was a significant linear relationship between CVD risk of people with HIV infection assessed by a non-specific equation (the Framingham risk equation) while this relationship was not significant when considering the specific CVD risk equation (the DAD risk equation). This discrepancy may be related to the fact that the DAD and Framingham risk scores do not measure exactly the same parameters. ${ }^{23}{ }^{24}$ Indeed, contrary to the Framingham risk equation, the DAD risk equation includes the use or not of some ART which is a specific parameter of HIV-infected populations. Notwithstanding, this difference is not sufficient enough to explain the discrepancy observed. Therefore, longitudinal studies need to be conducted in African populations to derive local CVD risk assessment tools, not only for the general population, but also for specific populations such as the HIV-infected population.

Unfortunately, we found no reason to explain these discrepant results. To the best of our knowledge, no previous study has investigated the relationship between the risk of CVD and insulin resistance as continuous variables in people living with HIV, especially those residing in Africa. However, evidence accumulated from systematic reviews, cross-sectional and prospective cohort studies point in favour of an increased risk of developing 
Open Access

Table 1 Characteristics of the study population

\begin{tabular}{|c|c|c|c|c|}
\hline & Overall $(n=452)$ & Women $(n=361)$ & Men $(n=91)$ & $\mathbf{p}$ \\
\hline \multicolumn{5}{|l|}{ General characteristics } \\
\hline Mean age (years) & $44.4 \pm 9.8$ & $43.7 \pm 9.9$ & $47.2 \pm 8.8$ & 0.001 \\
\hline Unmarried, n (\%) & $251(55.5)$ & $227(62.9)$ & $24(26.4)$ & $<0.001$ \\
\hline Secondary education or higher, $\mathrm{n}(\%)$ & $289(63.9)$ & 227 (62.9) & $62(68.1)$ & 0.351 \\
\hline Urban residence, n (\%) & $381(84.3)$ & $305(84.5)$ & $76(83.5)$ & 0.820 \\
\hline Unemployed, n (\%) & $219(48.5)$ & $196(54.3)$ & $23(25.3)$ & $<0.001$ \\
\hline Family past history of premature CVD, $\mathrm{n}(\%)$ & $46(10.2)$ & $36(10.0)$ & $10(11.0)$ & 0.774 \\
\hline Tobacco use, n (\%) & $27(6.0)$ & $10(2.8)$ & $17(18.7)$ & $<0.001$ \\
\hline \multicolumn{5}{|l|}{ HIV infection } \\
\hline ART use, $\mathrm{n}(\%)$ & $400(88.5)$ & $328(90.9)$ & $72(79.1)$ & 0.002 \\
\hline $\begin{array}{l}\text { Median duration of ART in months (25th-75th } \\
\text { percentile) }\end{array}$ & $72(35-108)$ & $72.0(34.0-108.0)$ & $74.0(36.0-106.5)$ & 0.971 \\
\hline First-line treatment, n (\%) & $373 / 400(93.3)$ & $304 / 328(92.7)$ & 69/72 (95.8) & 0.442 \\
\hline NVP, n (\%) & $78 / 373$ (20.9) & $67 / 304(22.0)$ & $11 / 69(15.9)$ & 0.261 \\
\hline EFV, n (\%) & 295/373 (79.1) & 237/304 (78.0) & $58 / 69(84.1)$ & 0.261 \\
\hline PI, n (\%) & $27 / 400(6.8)$ & $24 / 328(7.3)$ & $33 / 72(4.2)$ & 0.442 \\
\hline \multicolumn{5}{|l|}{ Clinical characteristics } \\
\hline Mean systolic blood pressure $(\mathrm{mmHg})$ & $123.4 \pm 22.5$ & $122.6 \pm 23.0$ & $126.5 \pm 20.3$ & 0.120 \\
\hline Mean diastolic blood pressure (mmHg) & $81.3 \pm 13.5$ & $81.3 \pm 13.6$ & $81.1 \pm 13.2$ & 0.909 \\
\hline Hypertension, n (\%) & $60(13.3)$ & 48 (13.3) & $12(13.2)$ & 0.978 \\
\hline Mean body mass index $\left(\mathrm{kg} / \mathrm{m}^{2}\right)$ & $25.8 \pm 5.3$ & $26.2 \pm 5.5$ & $24.0 \pm 3.9$ & $<0.001$ \\
\hline Obesity, n (\%) & $218(48.0)$ & $188(52.1)$ & 29 (31.9) & 0.001 \\
\hline Mean waist circumference (cm) & $82.1 \pm 11.6$ & $82.3 \pm 11.9$ & $81.0 \pm 10.5$ & 0.303 \\
\hline Abdominal obesity, n (\%) & $195(43.1)$ & $185(51.2)$ & $10(11.0)$ & $<0.001$ \\
\hline Mean hip circumference $(\mathrm{cm})$ & $95.1 \pm 11.2$ & $96.0 \pm 12.0$ & $91.4 \pm 8.8$ & 0.001 \\
\hline Mean waist/hip ratio & $0.86 \pm 0.07$ & $0.88 \pm 0.07$ & $0.89 \pm 0.06$ & $<0.001$ \\
\hline \multicolumn{5}{|l|}{ Biological characteristics } \\
\hline Median CD4 count (cells $/ \mathrm{mm}^{3}$ ) & $375(245-532)$ & $375(245-532)$ & $365(257-504)$ & 0.926 \\
\hline Mean fasting glycaemia (mmol/L) & $5.1 \pm 0.9$ & $5.1 \pm 0.7$ & $5.2 \pm 1.3$ & 0.236 \\
\hline Diabetes, n (\%) & $9(2.0)$ & $6(1.7)$ & $3(3.3)$ & 0.318 \\
\hline Mean total cholesterol (mmol/L) & $4.5 \pm 1.0$ & $4.5 \pm 1.0$ & $4.3 \pm 1.1$ & 0.238 \\
\hline Hypercholesterolaemia, n (\%) & $26(5.8)$ & $22(6.1)$ & $4(4.4)$ & 0.534 \\
\hline Mean HDL-C (mmol/L) & $1.7 \pm 0.6$ & $1.7 \pm 0.6$ & $1.5 \pm 0.6$ & 0.003 \\
\hline Low HDL-C, n (\%) & $106(23.5)$ & 85 (23.5) & $21(23.1)$ & 0.925 \\
\hline Mean triglycerides (mmol/L) & $1.0 \pm 0.5$ & $1.0 \pm 0.4$ & $1.1 \pm 0.6$ & 0.012 \\
\hline Hypertriglyceridaemia, n (\%) & $35(7.7)$ & $25(6.9)$ & $10(11.0)$ & 0.195 \\
\hline Mean LDL-C (mmol/L) & $2.3 \pm 0.9$ & $2.3 \pm 0.9$ & $2.3 \pm 1.0$ & 0.788 \\
\hline High LDL-C, n (\%) & $17(3.8)$ & $13(3.6)$ & $4(4.4)$ & 0.722 \\
\hline Any dyslipidaemia, n (\%) & $153(33.8)$ & $122(33.8)$ & $31(34.1)$ & 0.961 \\
\hline \multicolumn{5}{|l|}{ Median 5-year CVD risk } \\
\hline DAD equation & $0.6 \%(0.3-1.3)$ & $0.5 \%(0.3-0.9)$ & $1.4 \%(0.8-2.7)$ & $<0.001$ \\
\hline Framingham equation & $0.7 \%(0.2-2)$ & $0.5 \%(0.2-1.5)$ & $1.8 \%(0.9-4)$ & $<0.001$ \\
\hline
\end{tabular}

Values are count (percentages), mean \pm SD deviation or median (25th-75th percentiles).

ART, antiretroviral therapy; CVD, cardiovascular disease; EFV, efavirenz; HDL-C, high-density lipoprotein cholesterol; LDL-C, low-density lipoprotein cholesterol; NVRP, nevirapine; PI, protease inhibitor. 
Table 2 Relationship between HOMA-IR index, others factors and CVD risk, univariable analysis

\begin{tabular}{|c|c|c|c|c|}
\hline \multirow[b]{2}{*}{ Variables } & \multicolumn{2}{|c|}{ CVD risk with DAD equation } & \multicolumn{2}{|c|}{ CVD risk with Framingham equation } \\
\hline & Unadjusted $\beta$ & $\mathbf{p}$ & Unadjusted $\beta$ & $\mathbf{p}$ \\
\hline HOMA-IR index & 0.03 & 0.717 & 0.28 & 0.002 \\
\hline \multicolumn{5}{|l|}{ Socio-demographic characteristics } \\
\hline Occupation (employed/unemployed) & -0.08 & 0.105 & -0.08 & 0.109 \\
\hline Education (secondary or high/primary or less) & -0.12 & 0.013 & -0.10 & 0.042 \\
\hline Place of residence (urban/rural) & -0.01 & 0.868 & -0.06 & 0.231 \\
\hline Physical activity (yes/no) & 0.07 & 0.155 & 0.06 & 0.202 \\
\hline Hazardous alcohol consumption (yes/no) & 0.03 & 0.513 & -0.05 & 0.311 \\
\hline \multicolumn{5}{|l|}{ Clinical characteristics } \\
\hline Past history of CVD (yes/no) & l & I & 0.04 & 0.463 \\
\hline Body mass index & 0.01 & 0.9 & 0.15 & 0.002 \\
\hline Waist circumference & 0.13 & 0.008 & 0.25 & $<0.001$ \\
\hline Hip circumference & 0.01 & 0.794 & 0.15 & 0.002 \\
\hline WHO clinical stages ( 3 or $4 / 1$ or 2 ) & 0.01 & 0.797 & 0.00 & 0.993 \\
\hline Duration of HIV infection & 0.12 & 0.014 & 0.10 & 0.035 \\
\hline ART (yes/no) & / & I & 0.01 & 0.783 \\
\hline ART line (second /first) & / & / & -0.07 & 0.193 \\
\hline ART duration & / & l & 0.15 & 0.003 \\
\hline NRTIs (yes/no) & / & / & 0.01 & 0.783 \\
\hline NNRTIs (yes/no) & I & I & 0.05 & 0.287 \\
\hline Pls (yes/no) & / & / & -0.07 & 0.193 \\
\hline PI duration & / & l & 0.21 & 0.294 \\
\hline \multicolumn{5}{|l|}{ Biological characteristics } \\
\hline Virus serotype (2 and 1+2/1) & 0.01 & 0.726 & -0.23 & 0.650 \\
\hline CD4 count & -0.04 & 0.507 & 0.01 & 0.853 \\
\hline Viral load (detectable/undetectable) & 0.59 & 0.042 & 0.56 & 0.061 \\
\hline LDL-C & 0.22 & $<0.001$ & 0.28 & $<0.001$ \\
\hline Triglycerides & 0.09 & 0.059 & 0.10 & 0.043 \\
\hline Any dyslipidaemia (yes/no) & 0.05 & 0.302 & 0.17 & $<0.001$ \\
\hline Metabolic syndrome (yes/no) & 0.03 & 0.481 & 0.31 & $<0.001$ \\
\hline
\end{tabular}

* $\beta$, Regression coefficient.

ART, antiretroviral therapy; CVD, cardiovascular disease; HOMA-IR, homeostasis model assessment of insulin resistance; LDL-C, low-density lipoprotein cholesterol; NNRT, non-nucleoside reverse transcriptase inhibitor; NRTI, nucleoside reverse transcriptase inhibitor; PI, protease inhibitor.

CVD among subjects without diabetes presenting insulin resistance, despite some discrepancies between studies. $^{26} 27$ Indeed, partly corroborating our findings, Schmiegelow et al demonstrated a significant association in a univariable analysis between CVD risk estimated using the Framingham equation and insulin resistance assessed by the HOMA-IR index in a population of 15288 postmenopausal US women; but this association became non-significant in multivariable analysis after adjusting for HDL-C. ${ }^{28}$ Moreover, Howard et al did not find a significant relationship between insulin resistance and atherosclerosis in African Americans, which on the contrary was significant among Euro-Americans. ${ }^{29}$

Our study presents some limitations. The sampling method was not random, perhaps hindering any generalisation of our results. In the absence of locally-developed tools we used equations which were developed in Caucasian populations though the pattern of CVD may be different between Caucasians and black Africans. ${ }^{30}$ The cut-off used to define insulin resistance in our study was first used in a Peruvian HIV-infected population, ${ }^{5}$ this may have perhaps overestimated the prevalence of insulin resistance in our study given that basal insulin secretion may be higher in Africans. ${ }^{25}$ However, the results of the association between CVD risk and categorical insulin resistance (based on the HOMA-IR index cut-off) were confirmed by the results of the linear association between CVD risk and HOMA-IR. Finally, we used an indirect method to assess insulin resistance instead of the hyperinsulinemic euglycemic clamp which is the gold 
Table 3 Relationship between CVD risk, HOMA-IR index and other factors, multivariable analysis

\begin{tabular}{|c|c|c|c|c|}
\hline \multirow[b]{2}{*}{ Variables } & \multicolumn{2}{|c|}{ CVD risk with DAD equation } & \multicolumn{2}{|c|}{$\begin{array}{l}\text { CVD risk with Framingham } \\
\text { equation }\end{array}$} \\
\hline & Adjusted $\beta^{*}$ & p & Adjusted $\beta^{\star \star}$ & p \\
\hline HOMA-IR index & 0.18 & 0.429 & 0.64 & 0.001 \\
\hline \multicolumn{5}{|l|}{ Socio-demographic characteristics } \\
\hline Occupation (employed/unemployed) & 0.09 & 0.616 & -0.11 & 0.512 \\
\hline Education (secondary or high/primary or less) & 0.01 & 0.976 & 0.20 & 0.216 \\
\hline Place of residence (urban/rural) & / & / & 0.14 & 0463 \\
\hline Physical activity (yes/no) & 0.23 & 0.217 & 0.05 & 0.809 \\
\hline Hazardous alcohol consumption (yes/no) & / & / & / & / \\
\hline \multicolumn{5}{|l|}{ Clinical characteristics } \\
\hline Past history of CVD (yes/no) & / & l & / & 1 \\
\hline Body mass index & / & / & -0.34 & 0206 \\
\hline Waist circumference & 0.14 & 0.532 & 0.32 & 0.066 \\
\hline Hip circumference & / & / & 0.14 & 0.894 \\
\hline WHO clinical stages ( 3 or $4 / 1$ or 2 ) & l & I & I & / \\
\hline Duration of HIV infection & 0.54 & 0.022 & -0.10 & 0.702 \\
\hline ART (yes/no) & / & / & l & / \\
\hline ART line (second /first) & / & / & -0.18 & 0.331 \\
\hline ART duration & I & I & -0.20 & 0.971 \\
\hline NRTIs (yes/no) & / & / & I & / \\
\hline NNRTIs (yes/no) & / & / & / & / \\
\hline Pls (yes/no) & / & / & / & / \\
\hline PI duration & I & I & I & / \\
\hline \multicolumn{5}{|l|}{ Biological characteristics } \\
\hline Virus serotype (2 and 1+2/1) & / & I & I & l \\
\hline CD4 count & / & / & / & / \\
\hline Viral load (detectable/undetectable) & -0.31 & 0.117 & 0.14 & 0.393 \\
\hline LDL-C & -0.01 & 0.994 & -0.12 & 0.628 \\
\hline Triglycerides & -0.06 & 0.752 & -0.13 & 0.469 \\
\hline Any dyslipidaemia (yes/no) & / & / & / & / \\
\hline Metabolic syndrome (yes/no) & / & / & / & / \\
\hline
\end{tabular}

*Adjusted for: occupation, level of education, physical activity, waist circumference, duration of HIV infection, viral load, LDL-C and triglycerides.

${ }^{* \star}$ Adjusted for: occupation, level of education, place of residency, physical activity, body mass index, waist circumference, hip circumference, duration of HIV infection, ART duration, ART line, viral load, LDL-C and triglycerides.

$\ddagger \beta$, Regression coefficient.

ART, antiretroviral therapy; CVD, cardiovascular disease; HOMA-IR, homeostasis model assessment of insulin resistance; LDL-C, low-density lipoprotein cholesterol; NNRT, non-nucleoside reverse transcriptase inhibitor; NRTI, nucleoside reverse transcriptase inhibitor; PI, protease inhibitor.

standard. ${ }^{31}$ Nevertheless and to the best of our knowledge, this study is the first one which evaluated the direct relationship between CVD risk and insulin resistance as a continuous variables in sub-Saharan Africans. Furthermore, our sample size was large and we used rigorous methodological and statistical procedures to examine our research questions.

\section{CONCLUSION}

The relationship between insulin resistance and CVD risk may depend on the risk equation used. Further prospective cohort studies are warranted to better assess the relationship between CVD and insulin resistance in black African patients with HIV infection. In the meantime, preventing CVD in this population may call for implementation of a programme aiming to reduce, delay or prevent the occurrence of insulin resistance. 
Author affiliations

${ }^{1}$ Faculty of Medicine and Biomedical Sciences, University of Yaoundé 1, Yaoundé, Cameroon

${ }^{2}$ Faculty of Medicine, University of Paris Sud XI, Le Kremlin Bicêtre, France

${ }^{3}$ Department of Epidemiology and Public Health, Centre Pasteur of Cameroon, Yaoundé, Cameroon

${ }^{4}$ Department of Biochemistry and Physiological Sciences, Faculty of Medicine and Biomedical Sciences, University of Yaoundé 1, Yaoundé, Cameroon

${ }^{5}$ Laboratory of Biochemistry, University Teaching Hospital, Yaoundé, Cameroon

${ }^{6}$ Department of Public Health, Faculty of Medicine and Biomedical Sciences, University of Yaoundé 1, Yaoundé, Cameroon

${ }^{7}$ Department of Internal Medicine and Specialities, Faculty of Medicine and Biomedical Science, University of Yaoundé 1, Yaoundé, Cameroon

${ }^{8}$ Department of Biochemistry, Faculty of Science, University of Yaoundé I, Yaoundé, Cameroon

${ }^{9}$ Laboratory of Molecular Medicine and Metabolism, Biotechnology Center, University of Yaoundé 1, Yaoundé, Cameroon

${ }^{10}$ National Obesity Center, Yaoundé Central Hospital, Yaoundé, Cameroon

${ }^{11}$ Cardiology Unit, Yaoundé Central Hospital, Yaoundé, Cameroon

${ }^{12}$ Non-Communicable Diseases Research Unit, South African Medical Research Council, Cape Town, South Africa

${ }^{13}$ Department of Medicine, Groote Schuur Hospital and University of Cape Town, Cape Town, Cameroon

Acknowledgements Our gratitude goes to the physicians and nurses of the HIV outpatient clinic of the Yaoundé Central Hospital, to the personnel of the biochemistry laboratory of the Yaoundé University Teaching Hospital and that of the Laboratory of Molecular Medicine and Metabolism of the University of Yaoundé 1 Biotechnology Centre for their assistance during recruitment of participants and/ or biochemical measurements. The authors are also grateful to all those who have volunteered to take part in this study.

Contributors Conception and design: SRNN, ES, APK, FKA, VJAM. Participant recruitment and data collection: SRNN. Data analysis: SRNN, ES, APK, FKA, JJRB. Manuscript drafting: SRNN. Manuscript revision: APK, MYD, ES, JJRB, JRNN, VJAM, FKA, LKM, JAM, JCK, SL, MGF. Final approval of the version to be submitted: all authors.

Competing interests None declared.

Patient consent Obtained.

Ethics approval The study was approved by the Cameroon National Ethics Committee for Human Health Research (Ethical approval No 2015/12/710/CE/ CNERSH/SP). All participants singed a consent form.

Provenance and peer review Not commissioned; externally peer reviewed.

Data sharing statement All available data are included in this manuscript.

Open Access This is an Open Access article distributed in accordance with the Creative Commons Attribution Non Commercial (CC BY-NC 4.0) license, which permits others to distribute, remix, adapt, build upon this work non-commercially, and license their derivative works on different terms, provided the original work is properly cited and the use is non-commercial. See: http://creativecommons.org/ licenses/by-nc/4.0/

(c) Article author(s) (or their employer(s) unless otherwise stated in the text of the article) 2017. All rights reserved. No commercial use is permitted unless otherwise expressly granted.

\section{REFERENCES}

1. Fact sheet 2015 [Internet]. http://www.unaids.org/en/resources/ca mpaigns/HowAIDSchangedeverything/factsheet (accessed 27 Mar 2016).

2. Kiage JN, Heimburger DC, Nyirenda CK, et al. Cardiometabolic risk factors among HIV patients on antiretroviral therapy. Lipids Health Dis 2013:12:50.

3. Triant VA, Lee $\mathrm{H}$, Hadigan $\mathrm{C}$, et al. Increased acute myocardial infarction rates and cardiovascular risk factors among patients with human immunodeficiency virus disease. J Clin Endocrinol Metab 2007;92:2506-12.

4. Boccara F, Meuleman C, Ederhy S, et al. Atteinte cardiovasculaire au cours de l'infection par le VIH. EMC - Cardiologie 2009;4:1-7.
5. Guillen MA, Mejia FA, Villena J, et al. Insulin resistance by homeostasis model assessment in HIV-infected patients on highly active antiretroviral therapy: cross-sectional study. Diabetol Metab Syndr 2015;7:49.

6. Leclercq P, Roudiere L, Viard J. Complications graves des traitements antirétroviraux. Réanimation 2004;13:238-48.

7. Carr A, Samaras K, Chisholm DJ, et al. Pathogenesis of HIV1-protease inhibitor-associated peripheral lipodystrophy, Hyperlipidaemia, and insulin resistance. Lancet 1998;351:1881-3.

8. Bergersen BM, Sandvik L, Bruun JN, et al. Elevated Framingham risk score in HIV-positive patients on highly active antiretroviral therapy: results from a Norwegian study of 721 subjects. Eur J Clin Microbiol Infect Dis 2004;23:625-30.

9. Friis-Møller N, Weber R, Reiss P, et al. Cardiovascular disease risk factors in HIV patients--association with antiretroviral therapy. Results from the DAD study. AIDS 2003;17:1179-93.

10. Addictauvergne. Evaluation de la consommation d'alcool : questionnaire AUDIT [Internet]. http://www.addictauvergne.fr/echelleaddiction/audit-alcool/ (accessed 2015 Nov 21).

11. Anstey KJ, Kingston A, Kiely KM, et al. The influence of smoking, sedentary lifestyle and obesity on cognitive impairment-free life expectancy. Int J Epidemiol 2014;43:1874-83.

12. Améliorer l'accès aux traitements antirétroviraux dans les pays à ressources limitées - Recommandations pour une approche de santé publique: Annexe 1. Système OMS de classification des stades de l'infection et de la maladie à VIH chez l'adulte et l'adolescent [Internet]. http://apps.who.int/medicinedocs/fr/d/Js5514f/19.html (accessed 23 Jul 2015).

13. Obesity: preventing and managing the global epidemic. Report of a WHO consultation. World Health Organ Tech Rep Ser 2000;894:i1xii253.

14. IDF Worldwide Definition of the metabolic syndrome | International Diabetes Federation [Internet]. http://www.idf.org/metabolicsyndrome (accessed 28 Feb 2016).

15. 1999 World Health Organization-International Society of Hypertension Guidelines for the management of Hypertension. Guidelines Subcommittee. J Hypertens 1999:17:151-83.

16. Expert Panel on Detection, Evaluation, and Treatment of High Blood Cholesterol in Adults. Executive Summary of the Third Report of the National Cholesterol Education Program (NCEP) Expert Panel on detection, evaluation, and treatment of high blood cholesterol in adults (Adult treatment panel III). JAMA 2001;285:2486-97.

17. WHO. Definition and diagnosis of diabetes mellitus and intermediate hyperglycaemia [Internet]: WHO. http://www.who.int/diabetes/ publications/diagnosis_diabetes2006/en/ (accessed 28 Feb 2016).

18. Anderson KM, Odell PM, Wilson PW, et al. Cardiovascular disease risk profiles. Am Heart J 1991;121(1 Pt 2):293-8.

19. Friis-Møller N, Thiébaut R, Reiss $P$, et al. Predicting the risk of cardiovascular disease in HIV-infected patients: the data collection on adverse effects of anti-HIV drugs study. Eur J Cardiovasc Prev Rehabil 2010;17:491-501.

20. Matthews DR, Hosker JP, Rudenski AS, et al. Homeostasis model assessment: insulin resistance and beta-cell function from fasting plasma glucose and insulin concentrations in man. Diabetologia 1985;28:412-9.

21. Bursac Z, Gauss $C H$, Williams DK, et al. Purposeful selection of variables in logistic regression. Source Code Biol Med 2008;3:17.

22. Armstrong NM, Meoni LA, Carlson MC, et al. Cardiovascular risk factors and risk of incident depression throughout adulthood among men: the Johns Hopkins precursors Study. J Affect Disord 2017;214:60-6.

23. Mashinya F, Alberts M, Van Geertruyden JP, et al. Assessment of cardiovascular risk factors in people with HIV infection treated with ART in rural South Africa: a cross sectional study. AIDS Res Ther 2015;12:42

24. Nery MW, Martelli CM, Silveira EA, et al. Cardiovascular risk assessment: a comparison of the Framingham, PROCAM, and DAD equations in HIV-infected persons. Sci World J 2013;2013.

25. Haffner SM, D'Agostino R, Saad MF, et al. Increased insulin resistance and insulin secretion in nondiabetic African-Americans and Hispanics compared with non-Hispanic whites. The insulin resistance Atherosclerosis Study. Diabetes 1996;45:742-8.

26. Hedblad B, Nilsson P, Engström G, et al. Insulin resistance in nondiabetic subjects is associated with increased incidence of myocardial infarction and death. Diabet Med 2002;19:470-5.

27. Banerjee D, Biggs ML, Mercer L, et al. Insulin resistance and risk of incident heart failure: cardiovascular Health Study. Circ Heart Fail 2013;6:364-70.

28. Schmiegelow MD, Hedlin $\mathrm{H}$, Stefanick ML, et al. Insulin resistance and risk of Cardiovascular Disease in Postmenopausal Women: a 
Cohort Study from the Women's Health Initiative. Circ Cardiovasc Qual Outcomes 2015;8:309-16.

29. Howard G, O'Leary DH, Zaccaro D, et al. Insulin sensitivity and atherosclerosis. The Insulin Resistance Atherosclerosis Study (IRAS) Investigators. Circulation 1996;93:1809-17.

30. GBD 2013 Mortality and Causes of Death Collaborators. Global, regional, and national age-sex specific all-cause and cause-specific mortality for 240 causes of death, 1990-2013: a systematic analysis for the global burden of disease study 2013. Lancet 2015;385:117-71.

31. Glucose clamp technique: a method for quantifying insulin secretion and resistance. - PubMed - NCBI [Internet]. http://www.ncbi.nlm.nih gov/pubmed (accessed 20 Oct 2015). 